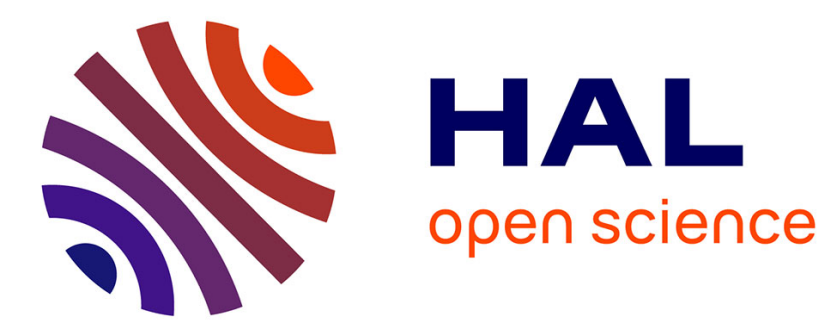

\title{
Social Categories and Group Preference Disputes: The Aversion to Winner-Take-All Solutions
}

\author{
Stephen M. Garcia, Dale T. Miller
}

\section{To cite this version:}

Stephen M. Garcia, Dale T. Miller. Social Categories and Group Preference Disputes: The Aversion to Winner-Take-All Solutions. Group Processes and Intergroup Relations, 2007, 10 (4), pp.581-593. 10.1177/1368430207084721 . hal-00571672

\section{HAL Id: hal-00571672 \\ https://hal.science/hal-00571672}

Submitted on 1 Mar 2011

HAL is a multi-disciplinary open access archive for the deposit and dissemination of scientific research documents, whether they are published or not. The documents may come from teaching and research institutions in France or abroad, or from public or private research centers.
L'archive ouverte pluridisciplinaire HAL, est destinée au dépôt et à la diffusion de documents scientifiques de niveau recherche, publiés ou non, émanant des établissements d'enseignement et de recherche français ou étrangers, des laboratoires publics ou privés. 


\title{
Social Categories and Group Preference Disputes: The Aversion to Winner-Take-All Solutions
}

\author{
Stephen M. Garcia \\ University of Michigan \\ Dale T. Miller \\ Stanford University
}

\begin{abstract}
Six studies explored the hypothesis that third parties are averse to resolving preference disputes with winner-take-all solutions when disputing factions belong to different social categories (e.g. gender, nationality, firms, etc.) versus the same social category. Studies 1-3 showed that third parties' aversion to winner-take-all solutions, even when they are based on the unbiased toss of a coin, is greater when the disputed preferences correlate with social category membership than when they do not. Studies 4-6 suggested that reluctance to resolve inter-category disputes in a winner-take-all manner is motivated by a desire to minimize the affective disparity - the hedonic gap-between the winning and losing sides. The implication is that winner-take-all outcomes, even those that satisfy conditions of procedural fairness, become unacceptable when disputed preferences cleave along social category lines.
\end{abstract}

KEYWORDS behavioral economics, competition, decision-making, distributive justice, group disputes, social categories, social comparison

How should a high school principal respond to an informal poll about music for the upcoming prom if half the students want one type of music played and half want another? The principal could conceivably resolve this conflict in various ways. We believe, however, that the acceptability of the possible solutions will depend on whether the division is associated with social category membership. In particular, our research explores the hypothesis that third party deciders are less comfortable resolving preference disputes with winner-take-all solutions when disputing factions belong to different social categories than when they belong to the same social category.
Tossing a coin in the case of the differing musical preferences, for example, would be a less acceptable mode of resolution when the preferences are divided along ethnic or gender lines than when they are not.

Based on theory and research from the social categorization and social comparison

\footnotetext{
$\overline{\text { Author's note }}$

Address correspondence to Stephen Garcia, University of Michigan, 4126 Weill Hall, Ann Arbor, MI 48109-3091, USA [email: smgarcia@umich.edu]
} 
literatures (e.g. Garcia, Tor, Bazerman, \& Miller, 2005; McGarty, 1999; Wenzel, 2001, 2002), we propose that third parties' expectations about the magnitude of the affective disparity (hedonic gap) that arises between the winners and losers of a preference dispute are greater when the disputed preferences cleave along social category lines than when they do not. Consequently, people become more averse to winner-take-all solutions in the former case than in the latter. We do not deny, of course, that preferences can themselves form the basis of group membership. As a long line of research in the minimal group tradition suggests (see Brewer, 1979; Tajfel, 1969, 1981), people are quick to form group identities around even the most trivial characteristics (e.g. preferences for one geometric shape over another). Our claim is simply that any identity polarization that emerges over a preference dispute is compounded when the disputed preferences correlate with other meaningful social category memberships.

\section{Why social categories matter}

Winner-take-all distributions are commonly imposed when assets or liabilities cannot be divided equally or when statistical randomization (e.g. through a coin toss or lottery) is desired (Beggan, Platow, \& McClintock, 1991; Bolton, Brandts, \& Ockenfels, 2005; Elster, 1989, 1992). Previous research has already begun to explore the intersection of social categories and distributive outcomes. Perceptions of distributive justice, for instance, vary depending on whether people belong to the same or different social categories (e.g. Wenzel, 2001, 2002). Although people may feel more entitled to outcomes that benefit themselves rather than others, relevant social categories can dramatically alter perceptions of entitlement. Wenzel (2002), for example, explored how perceived entitlement to common pay changes with the level of identification with a social category. Wenzel found that the more strongly participants identified with an ingroup, the more likely they were to forego self-interest and reward a fellow ingroup member who exemplified the strengths of the group.
But why should the fact that different sides in a dispute belonging to the same or different social categories affect the willingness of a third party to impose a solution that sees one of them win and the other lose? The answer, we contend, is that third parties believe winner-take-all solutions to disputes in which preferences divide along social category lines will create a hedonic gap — an affective disparity-between the winners and losers. This hypothesis is consistent with the widely accepted premises that (a) people attach emotional value to their social category memberships (Abrams \& Hogg, 1988, 1999; Deaux, 1996; Hogg \& Abrams, 1990; Tajfel, 1981) and (b) competitive events can make more salient the social categories involved in inter-category conflict (Brewer, 1979). It is also consistent with research that shows that people's willingness to tolerate disadvantageously unequal outcomes (e.g. we get $\$ 400 /$ they get $\$ 500$ ) diminishes as a function of the meaningfulness of the social categories involved (Garcia et al., 2005).

In a series of studies, Garcia et al. (2005) found that resource allocation recipients were less averse to unequal allocations when all recipients were members of the same social category than when they belonged to different social categories. For example, in one study, Garcia and his colleagues asked University of Michigan (UM) participants to imagine a hotel vacancy dilemma involving traveling groups of students from UM and Harvard. The participants were asked to recommend a solution: Should both UM and Harvard student groups stay at a 1-star motel (Option A), or, for reasonable logistical reasons, should UM students stay at a 2-star hotel and Harvard students at a 4-star hotel (Option B)? Note that Option B is the quality maximizing option, but produces disadvantageous inequality. A control condition was similar, except that two UM groups were traveling together and Option B specified that the participant herself/himself would be put in the 2-star hotel. Results showed that the UM participants in the control condition maximized the quality of the hotel in which they would be staying themselves (choosing Option B). However, in the experimental condition, the UM participants opted for a lower quality hotel 
(choosing Option A), presumably because they anticipated that the pain of upward social comparison (Brickman \& Bulman, 1977) caused by Harvard students enjoying a better hotel was greater than the pain caused by residing in a 1-star rather than a 2-star hotel themselves.

Garcia et al. (2005) focused on the willingness of group members themselves to tolerate disadvantageous inequality depending on whether the allocation occurred across or within social categories. The following studies focused on the impact of this factor on third party deciders. Although third parties do not experience the pain of upward social comparison per se, we contend that they do expect the affective disparity, or hedonic gap, between winning and losing sides of a winner-take-all solution to be greater in inter-category than intra-category disputes. In other words, just as payoff recipients prefer equal outcomes in inter-category allocations, in order to avert the pain of upward social comparison, so too will third parties become averse to winnertake-all outcomes in inter-category disputes, in order to preempt a hedonic gap. And to the extent that people assume a winner-take-all outcome will produce a greater hedonic gap between winners and losers in an inter-category compared to an intra-category dispute, we predict that such solutions will be chosen less often in the former than in the latter case.

\section{Study 1: Flipping a coin}

Study 1 examined whether the preferred mode of resolution for disputes between individuals depends on the relation between the disputants. Our prediction was that the aversion to a winner-take-all solution would be greater when the disputants belonged to different social categories than when they belonged to the same social category.

\section{Method}

Participants Forty-nine University of Michigan undergraduates volunteered to participate. Research assistants recruited the students in the lobby of a campus library by asking them if they would be willing to participate in a short survey on decision-making.
Procedure Participants read about an intracategory or an inter-category preference dispute involving hotel arrangements for the 'UM Class Reunion of 1994'. None of the participants belonged to this 10 -year reunion class. The intra-category version read as follows:

The Class of 1994 is deciding where to host their class reunion. Six hundred alumni were asked to rank a list of seven possible hotels. As you can see below, the alumni are divided on their first choice: Half the alumni want the Marriott and half the alumni want the Hyatt. In fact, as you can see below, they do not agree until their fourth choice, the Radisson Hotel.

Participants were then shown a table listing the seven top hotel choices of the two groups. The preferences of one side (in order of preference) were: Marriott, Westin, Hyatt, Radisson, Hilton, Sheraton, and Doubletree. The preferences of the other side were: Hyatt, Doubletree, Marriott, Radisson, Westin, Hilton, and Sheraton. The Radisson was the agreed fourth choice and the first choice of each side was actually the third choice of the other. The inter-category version was identical, except that 'In-state and out-of-state alumni are divided over their first choice. Instate alumni want the Marriott and out-of-state alumni want the Hyatt'. All participants were then asked, 'If only the following options were available, where should the reunion be held?' The two options were (a) flip a coin for their first choice $($ Heads $=$ Marriott, Tails $=$ Hyatt $)$; and (b) choose the Radisson. Participants who expressed interest after completing the survey were then told more about the study.

\section{Results and discussion}

The results showed that $84 \%$ of the participants in the intra-category condition favored tossing a coin to decide which of the two groups got their first choice hotel. The remaining $16 \%$ favored the Radisson Hotel as a compromise. A very different pattern emerged in the inter-category condition. There only $58 \%$ favored tossing a coin, while $42 \%$ favored choosing the Radisson Hotel as a compromise. The two conditions differed significantly in their preferences $\left(\chi^{2}(1)=3.95\right.$, $p<.05)$. Although random solutions, such as 
tossing a coin, are generally viewed as procedurally fair (Blount, 1995; Bolton, et al., 2005), the results clearly showed that people are not as comfortable accepting winner-take-all solutions when the disputing parties belong to different social categories. Indeed, a sizable fraction of participants $(42 \%)$ chose a suboptimal option for both parties in order to avoid a winner-takeall solution.

\section{Study 2: An arbiter}

Study 1 found that people did not want to resolve an inter-category dispute by tossing a coin. This result could reflect an aversion to winner-takeall solutions for such disputes, but it could also simply reflect a reluctance to resolve a dispute by chance when groups from different social categories are involved. Study 2 thus sought to demonstrate that discomfort with winner-takeall solutions in inter-category disputes does not depend on the means (random or not) by which the winners and losers are determined. In this study, the winner-take-all decision was made by an arbiter rather than by chance.

\section{Method}

Participants Thirty-eight undergraduate students participated in a questionnaire study that was part of a larger experimental session conducted at the Harvard Business School. Participants received US $\$ 15$ to $\$ 30$ for participating in the session. The variation in pay reflected a number of other studies bundled with ours in which students had the opportunity to earn more or less money. However, it is doubtful that there could have been any differences in their responses due to pay, because participants did not know their total earnings until after the entire session.

Procedure Participants read a brief scenario about a dispute over the color of the Merrill Lynch company logo. The intra-category version read as follows: 'The American office of Merrill Lynch is deciding the color of the company logo. Half the office wants the color blue, while the other half wants the color red'. The inter-category version was identical, except that 'The American office wants the color blue and the French office wants the color red'. Participants were then asked: 'If only the following options were available, how should the color of the company logo be determined: (a) solve immediately by going to an arbiter (arbiter decides blue or red or (b) solve by using resources to search for a compromise?' Afterward, all participants were given a written description of the study's purpose.

\section{Results and discussion}

The results paralleled those of Study 1 . In the intra-category condition, $53 \%$ of the participants recommended resolving the dispute through an arbiter, whereas only $21 \%$ of the participants chose the arbiter in the inter-category condition. The two conditions again differed significantly in their preferences $\left(\chi^{2}(1)=4.07, p<.05\right)$. This finding minimizes the counter-explanations that third parties are averse to flipping a coin in inter-category disputes because of its chance component or its potentially frivolous appearance. As Study 2 illustrates, the aversion to winnertake-all solutions in inter-category disputes is not restricted to circumstances where the outcome is determined by chance. In this study, the winner-take-all solution was determined by a deliberative agent-an arbiter.

\section{Study 3: A common preference}

The preference disputes in the first two studies were not ones that would evoke a priori theories involving particular social identities. Nevertheless, participants may have inferred that preference differences were related to group identity (e.g. Prentice \& Miller, 2006; Yzerbyt, Rocher, \& Schadron, 1997). That is, once they learned that preferences and group membership covaried, participants could have assumed that the dispute was somehow significant for group identity. If so, then the observed aversion to winner-take-all solutions in inter-category disputes could have reflected the perception that the domains in which such disputes occur are more important or central to the categories involved. To rule out this possibility, Study 3 shifted the focus from a situation where the 
disputants had different preferences to one in which they had the same preference.

\section{Method}

Participants Altogether, 250 undergraduates at the University of Michigan, randomly selected from the student directory, were contacted by email and invited to participate in an online study. Seventy-three of them (approximately $29 \%$ ) agreed to do so.

Procedure Everyone read the following scenario: 'Imagine that 1000 hungry high school students from around the country took a break to eat lunch at a one-day conference. The conference dining room could only seat half the students immediately, whereas the other half would have to wait 20 minutes'. Of course, this presumes that the students at the conference would have preferred to eat lunch immediately. Participants were then asked how they would solve this problem. Participants in the control condition chose between '(A) flip a coin for who gets seated first (heads = last names A-L; tails = last names M-Z) or (B) have everyone wait 20 minutes to be seated'. Of course, Option B implies that the dining room is not quite ready (for whatever reason) to seat everyone. Participants in the inter-category condition saw a modified wording of Option (A), namely 'flip a coin for who gets seated first (heads = girls, tails $=$ boys $)^{\text {'. }}$ Note that although the use of last names A-L vs. $\mathrm{M}-\mathrm{Z}$ in the control condition arguably reflects different social categories, such categories seem much less meaningful than gender, and thus offer a suitable control condition for this study.

\section{Results and discussion}

In the control condition, $56 \%$ of participants were willing to flip a coin, thereby letting half of the students eat before the other half (based on the first letter of their last names), whereas only $28 \%$ of participants in the inter-category condition were willing to flip a coin when it meant one gender would eat before the other. This difference between conditions was significant $\left(\chi^{2}(1)=5.71\right.$, $p<.05)$. In other words, participants were willing to favor one set of students over the other when the students were divided alphabetically, but not when they were divided by gender. Thus, the aversion to winner-take-all outcomes in intercategory disputes does not require an inference that preferences correlated with social categories are more deeply held or symbolically important. The preference to eat first was equally important to everyone.

\section{Study 4: Outcomes and the hedonic gap}

Studies 1-3 found that participants avoided a dispute resolution procedure that yielded a winner-take-all solution when the disputants belonged to different social categories. Strictly speaking, however, we are less interested in people's attitudes toward the procedures that yield winner-take-all outcomes than we are in people's attitudes toward the winner-takeall outcomes themselves. Accordingly, Study 4 focused on participants' feelings about the acceptability of winner-take-all outcomes, not the procedures that produced those outcomes. Study 4 also eliminated any references to particular social categories to ensure that participants' choices in the inter-category conditions were not influenced by any partiality they might have for one category over another (Crisp \& Hewstone, 1999, 2000).

Study 4 also sought more direct evidence that the aversion to winner-take-all outcomes in inter-category disputes is driven by a desire to minimize the hedonic gap between winners and losers, as opposed to simply a concern for avoiding intergroup conflicts (see Schopler et al., 1995). Free response data were thus elicited from participants about the reasoning behind their choices (see Haddock \& Zanna, 1998).

\section{Method}

Participants Thirty-eight University of Michigan undergraduates (22 females and 16 males) completed a questionnaire that was included in a larger 'Questionnaire Day' packet. They were recruited through flyers posted around campus, as well as by research assistants standing near the data collection venue. Participants were paid US $\$ 10$ for completing the entire packet, which required approximately an hour of their time. 
Procedure In a between-subjects design, participants were assigned to one of two conditions. The scenario in the intra-category condition read as follows: 'Imagine a college dorm is getting new carpet. Color preference is divided evenly. Half the students want red carpet and half want blue carpet'. The scenario in the inter-category condition was identical, except that: 'Color preference is divided evenly along religious lines. Students of one religion want red carpet and students of another religion want blue carpet'. In both conditions, participants were asked, 'Is it okay to have a winner-take-all outcome in which the carpet is ultimately red or blue? (YES or NO)'. They were then asked to explain their choices briefly. Participants were then paid for completing the questionnaire packet and given an opportunity to learn more about the details of the project.

Coding the open-ended responses Four undergraduate research assistants coded the reasons that participants gave for their choices. The experimenter trained the coders together, at the same time, offering written and oral instructions. The coders were blind to the research hypothesis, to the experimental conditions from which the materials they coded were drawn, and to the particular choices that were being justified. They first coded for evidence that participants had focused on the magnitude of the hedonic gap that would arise between disputants if a winner-take-all solution were used. The hedonic gap instructions were as follows:

Obviously, winning or losing is associated with different levels of happiness. The winners are happy and the losers are unhappy. We use the term "hedonic gap" to reflect the difference between the happiness of the winners and the unhappiness of the losers. To the extent the winners feel victorious and the losers feel defeated, the "hedonic gap" is large. On the other hand, to the extent that winners feel nominally happy and the losers nominally unhappy, the "hedonic gap" is small. Shortly, you will be rating a random list of comments. Your task will be to indicate a check next to every comment that reflects a concern for preempting this hedonic gap, as we've just discussed. Please read carefully through each of the comments.
We also coded responses for evidence that an aversion to winner-take-all solutions was based on a desire to minimize the potential for intergroup hostility. The group tension instructions were identical to the hedonic gap instructions, except for the following insertion: 'Often times when there is a dispute, people become concerned with preempting tension between two groups. We use the term "group tension" to reflect conflict or tension between groups. Shortly...' The coders received a spreadsheet with the participants' responses randomly arranged and made a check next to each response to indicate whether it reflected a concern for the hedonic gap and/or a concern for group tension. Statements coded as re-flecting a concern for preempting the hedonic gapincluded 'because only half would be satisfied and the other half would not', and statements of group tension included 'It creates tension between the two groups'.

\section{Results and discussion}

In the intra-category condition, $79 \%$ of the participants agreed that it was acceptable to have a winner-take-all outcome. However, in the inter-category condition, only $21 \%$ of the participants were willing to accept a winner-take-all outcome. This difference between conditions was significant $\left(\chi^{2}(d f=1)=12.7, p<.001\right)$. There was no significant effect of gender on participants' responses. The results support our claim that the aversion to winner-take-all procedures in inter-category disputes is based on the outcomes they produce, not on the procedures themselves.

Indices of the concern for preempting the hedonic gap and group tension were created by averaging the coders' check-marks. If all four coders checked something, then it received an index score of 1.00. If three coders checked it, then it received an index score of 0.75 . If two coders checked it, then it received an index score of 0.50 . If one coder checked it, then it received an index score of 0.25 . If no coder checked it, then it received an index score of 0 . Three participants did not respond to the open-ended question and thus were not included in the coding analysis. To assess coder 
reliability, we computed Cohen's kappa for each coder pair. Because there were four coders, there were six possible coder pairs. The kappa values for the hedonic gap ratings for the six pairings ranged from .77 to .25 , with a significance range from $p=.000$ to $p=.089$ and an average kappa of .44 and an average $p$ of .02. Only one pair of coders showed marginally significant agreement (kappa $=.25, p=.089)$. The Kappa values for the six coder pairings of the group tension ratings ranged from .66 to .42 , with a signi-ficance range from $p=.000$ to $p=.008$ (average kappa $=.51$, average $p=.003$ ). All of this indi-cates that the coding of both hedonic gap and group tension concerns was done reliably.

To better understand the role that hedonic gap and group tension concerns played in participants' choices, we conducted two separate mediation analyses (Kenny, Kashy, \& Bolger, 1998). First, as expected, a logistic regression $(B=2.64$, Wald $=11.0, p<.01)$ showed that dispute context $(1=$ intra-category, $2=$ inter-category $)$ was a significant predictor of outcome $(1=$ accepting or $2=$ not accepting a winner-take-all outcome). Second, a standard regression showed that dispute context was a significant predictor of the hedonic gap index scores $(\mathrm{B}=.47, \beta=.67$, $p<.001)$. Finally, when both dispute context and hedonic gap index scores were used to predict outcomes, a logistic regression showed that hedonic gap was a significant predictor of outcome ( $\mathrm{B}=12.3$, Wald $=7.4, p<.01$ ), but dispute context was not $(\mathrm{B}=.18$, Wald $=.02, p=.90)$. A Sobel's test also showed that the reduction in the regression coefficient for dispute context was significant (Sobel $=2.40, p<.05)$. Thus, it appears that concern with the magnitude of the hedonic gap mediates the relationship between dispute context and outcomes.

We also found that dispute context was a significant predictor of the group tension index scores $(\mathrm{B}=.30, \beta=.45, p<.01)$. However, when both dispute context and group tension index scores were used to predict outcomes, group tension was only a marginally significant predictor of outcomes ( $\mathrm{B}=4.47$, Wald $=3.8, p=.0502)$, and dispute context remained significant $(B=2.01$, Wald $=5.0, p<.05)$. Thus, group tension, though related to dispute context and outcomes, did not appear to mediate their relationship with one another. Supporting this claim, a follow-up logistic regression analysis of outcomes with both hedonic gap and group tension as predictors (along with dispute context) revealed that hedonic gap was significant $(\mathrm{B}=13.8$, Wald $=5.4, p<.05)$, but grouptension was not $(\mathrm{B}=-1.42$, Wald $=.18$, $p=.67)$.

It is important to note that the hedonic gap and group tension ratings were highly correlated $(r=.73, \mathrm{p}<.001)$. So (despite the results from our regression analyses) it is difficult to separate these two constructs. However, the results seem to indicate that the aversion people have for resolving inter-category disputes in a winnertake-all manner is not based solely on their fear that such outcomes will produce intergroup conflict. The belief that the gap in the emotional reactions of the winners and losers will be great is sufficient to steer third-party deciders away from winner-take-all solutions. People just don't want to create a situation that results in having winners and losers if the winner and losers will represent different social categories. Of course, when the preferences involve more serious issues than carpet color (e.g. one country wants to pursue nuclear technology, but another does not want that to happen), concerns about group conflict may play a stronger role, though the anticipation of a hedonic gap might still precede this concern.

\section{Study 5: Increasing the hedonic gap}

Study 4 produced evidence that people are concerned about the hedonic gap between winners and losers in inter-category disputes. Some of this evidence came from participants' justification for their choices. Such data can be valuable in uncovering psychological mechanisms (e.g. Haddock \& Zanna, 1998), but are not without limitations (see Nisbett \& Wilson, 1977). Accordingly, we manipulated the perceived magnitude of the hedonic gap in Study 5, so that we could more directly assess its role in the aversion to winner-take-all outcomes. Our prediction was that an aversion to winnertake-all outcomes in inter-category disputes 
would only occur when there was a potential hedonic gap.

\section{Method}

Participants Altogether, 103 undergraduates (49 females and 54 males) from the University of Michigan and Bowling Green State University completed a questionnaire that was included in a larger 'Questionnaire Day' packet. Students were recruited by flyers posted around campus advertising research on decision-making and attitudes. They were paid US $\$ 8$ for completing the entire packet, which required approximately 45 minutes of their time.

Procedure Participants in the high hedonic gap condition read the same scenario used in the inter-category condition of Study 4 ( '...Students of one religion want red carpet and students of another religion want blue carpet.'). Participants in the low hedonic gap condition read the same scenario, but with one additional sentence: 'Despite their preferences, neither side will be upset if the carpet is ultimately red or blue'. We focused on the inter-category context because the aversion to winner-take-all solutions is greatest in that context. Note that the control condition was identical to the intra-category condition of Study 4 ('....Half the students want red carpet and half want blue carpet.'). All participants were asked whether it was acceptable to resolve the dispute in a winner-take-all manner. Participants were then paid and given an opportunity to learn more about the details of the project.

\section{Results and discussion}

The results supported the prediction $\left(\chi^{2}(d f=1)=\right.$ $14.3, p<.01)$. Only $34 \%$ of participants in the high hedonic gap condition were willing to resolve the inter-category dispute with a winner-take-all outcome, compared to $70 \%$ of participants in the low hedonic gap condition. This difference between conditions was significant $\left(\chi^{2}(1)=8.90\right.$, $p<.01)$. Not surprisingly, $77 \%$ of participants in the control condition accepted a winner-take-all outcome; this percentage was not significantly different from the percentage found in the low hedonic gap condition $\left(c^{2}(1)=.35, p=.56\right)$. Again, there were no significant effects of gender on participants' responses.

These results suggest that people are reluctant to resolve inter-category disputes with winnertake-all outcomes only when they expect such an outcome to produce a large hedonic gap. When that concern is allayed, third parties are as comfortable with winner-take-all solutions in inter-category disputes as in intra-category disputes. Taken together, Studies 4 and 5 provide strong support for the claim that a concern with minimizing the hedonic gap between winners and losers mediates third parties' aversion to winner-take-all outcomes in inter-category disputes.

\section{Study 6: Social category meaningfulness}

Study 6 examined the hypothesis that the impact of a hedonic gap might depend on the meaningfulness of the social category dimension. Not all social categories are equally important to people (McGarty, 1999; Turner, Hogg, Oakes, Reicher, \& Wetherell, 1987), and not all intercategory disputes are equally meaningful to the disputants (e.g. McGarty, 1999; Haslam, McGarty, \& Brown, 1996). In Study 6, we thus manipulated the meaningfulness of the social categories involved in a dispute. By increasing the meaningfulness of the social categories, but holding the issue constant, we expected to increase the anticipated size of the hedonic gap between the winning and losing sides, thereby strengthening people's reluctance to resolve the dispute in a winner-take-all manner.

\section{Method}

Participants Seventy-six University of Michigan undergraduates (42 females and 34 males) completed a questionnaire that was included in a larger 'Questionnaire Day' packet. Students were recruited by flyers posted around campus advertising research on decision-making and attitudes. They were paid US $\$ 10$ for completing the entire packet, which required approximately an hour of their time. 


\section{Procedure}

Acceptance of a winner-take-all outcome In this study, we used a within-subjects design because we thought it would be more sensitive than a between-subjects design to the true strength of people's attitudes and preferences (see Camerer, 1995). Participants were asked how appropriate it would be to resolve a variety of inter-category disputes in a winner-take-all manner. Participants were asked to 'Imagine that an organization is planning to offer a new company benefit. Because disputes can often be divided along many different lines, the following five disputes represent different divisions that could occur within an organization'. At this point, participants read five different inter-category disputes. In every case, one side wanted a new 'fitness center' and the other side wanted 'dental care'.

The five social category divisions involved culture (one culture of employees wants fitness center vs. another culture of employees wants dental care), nationality (Japanese vs. French employees), coast (East Coast vs. West Coast employees), handedness (left-handed vs. righthanded employees), and water-taste preference (tap-water drinking vs. bottled-water drinking employees). ${ }^{1}$ After reading about each of these five disputes, participants responded to the question, 'How appropriate would it be to have a winner-take-all outcome in which the benefit is ultimately a new "fitness center" or "dental care"? ( $1=$ not appropriate, 7 = very appropriate)'. The order of the five disputes was rotated across participants. Again, in every case, the dispute was over differing preferences for the new company benefit-the fitness center versus dental care. What varied was the social category line along which these two preferences divided.

Coding the magnitude of the anticipated hedonic gap Five undergraduate students coded the size of the hedonic gap for each of the five disputes. Blind to the research hypothesis, and to the participants' ratings of the winner-take-all outcome, the coders were given instructions for coding the hedonic gap similar to those used in Study 4: 'Obviously, winning or losing is associated with different levels of happiness...' The coders then proceeded to rate the size of the hedonic gap for each of the disputes: 'Assume that a winner-takeall outcome occurred. Estimate the size of the "hedonic gap" between the side whose preference was chosen and the side whose preference was not chosen ( 1 = small gap, 7 = enormous gap) '. The disputes were presented in a random order for each rater.

\section{Results and discussion}

We first examined participants' ratings of the appropriateness of winner-take-all outcomes across the five disputes. In ascending order of appropriateness, these were: culture $(M=3.07, S D=1.79)$, nationality $(M=3.33, S D=1.76)$, coast $(M=3.63$, $S D=1.83)$, handedness $(M=3.72, S D=2.10)$, and water-taste preference $(M=3.76, S D=1.99)$. A repeated measures analysis of variance on these ratings showed significant differences across disputes $(F(4,300)=4.72 \mathrm{p}<.01)$.

Follow-up $t$ tests showed that culture $(t(75)=4.5$, $p<.001)$ and nationality $(t(75)=3.3, p<.01)$ were significantly different from the scale midpoint, and coast $(t(75)=1.8, p=.08)$ was marginally different from that point. Paired $t$ tests also showed that water-taste pre-ference was significantly different from culture $(t(75)=3.23, p<.01)$ and nationality $(t(75)=2.02, p<.05)$, and that culture was significantly different from handedness $(t(75)=3.09, p<.01)$, coast $(t(75)=2.84$, $p<.01)$, and nationality $(t(75)=2.79, p<.01)$. Nationality was marginally different from handedness $(t(75)=1.86, p=.07)$. Again, there were no significant gender effects.

As for the coders' ratings of the hedonic gap, we created an index by averaging across their responses. An intra-class correlation showed high consistency among the coders $(r=.75, p<.001)$. A repeated measures analysis of variance on their ratings also showed significant differences across disputes $(F(4,16)=16.50, p<.001)$. In descending order, the mean index scores were: culture $(M=5.6, S D=1.14)$, nationality $(M=5.0$, $S D=0.7)$, coast $(M=4.2, S D=1.1)$, handedness $(M=2.2, S D=0.8)$, and water-taste preference $(M=1.8, S D=0.8)$.

Follow-up $t$ tests showed that culture $(t(4)=3.1$, $p<.05)$, nationality $(t(4)=3.2, p<.05)$, handedness 
$(t(4)=4.8, p<.01)$, and water-taste $(t(4)=5.9$, $p<.01)$ were all significantly different from the scale midpoint. Additional $t$ tests revealed that water-taste was significantly different from coast $(t(4)=3.2, p<.05)$, nationality $(t(4)=8.6, p<.01)$, and culture $(t(4)=7.8$, $p<.01)$. Handedness was significantly different from nationality $(t(4)=7.5, p<.01)$ and culture $(t(4)=6.7, p<.01)$. Marginally different were handedness and coast $(t(4)=2.4, p=.08)$, and nationality and culture $(t(4)=2.4, p<.07)$.

Finally, a correlation analysis showed a strong inverse relationship between the five mean ratings of the anticipated winner-loser hedonic gaps and the five mean ratings of the appropriateness of winner-take-all outcomes $(r(4)=-.91$, $p<.05)$. Although this correlation could be interpreted in more than one way, it is consistent with the proposed link between an aversion to winner-take-all outcomes and the size of the hedonic gap between winners and losers. It thus complements the mediation analyses and hedonic gap manipulations of Studies 4 and 5. The results of Study 6 also reveal that the magnitude of the hedonic gap that people expect to arise between winners and losers can vary considerably across social categories. Whether those employees wanting dental care or those wanting a fitness center get their wish is expected to have much greater emotional impact when those requesting each represent different cultures than when they represent different handedness.

\section{General discussion}

Across a variety of issues and contexts, we found converging evidence that third parties are averse to resolving disputes between different social categories with winner-take-all solutions. Study 1 showed that in an inter-category dispute, people would rather select a mutually less preferred option than flip a coin to determine whose first preference will be chosen. Study 2 showed that the aversion to winner-take-all solutions also occurs when the final choice is made by an arbiter. Study 3 showed that the aversion does not depend on any naive theory people might have about how preferences are related to the identities of the social categories involved in the dispute. Study 4 showed that a concern for minimizing the hedonic gap mediates the relationship between dispute context and the aversion to winner-take-all outcomes. Study 5 provided further evidence for the hedonic gap mechanism-the aversion to winner-take-all outcomes diminished considerably when the possibility of a hedonic gap was removed. Finally, Study 6 showed that the meaningfulness of the social categories involved in a dispute moderates the magnitude of the expected hedonic gap and people's aversion to winner-take-all outcomes.

\section{Implications for management and policy making}

Experts from the conflict resolution literature have long recommended that third parties ensure procedural justice so that disputants will more readily accept distributive outcomes (e.g. Lind \& Tyler, 1988). What is striking about our research results is that third parties clearly become more concerned with distributive outcomes, specifically winner-take-all outcomes, than with procedural issues when preferences divide along social category lines. Even when a procedural mechanism (e.g. a coin toss) unequivocally treats disputing parties equally, third parties still seem disturbed by a winner-take-all outcome. Hence, uninvolved third parties, who are most capable of maximizing the joint gains between dissenting factions in competitive environments (Raiffa, 1982), may find it especially difficult to do so when one social category can objectively claim more value than another social category, regardless of the procedural mechanism. Giving disputants the opportunity to voice concerns (Thibaut \& Walker, 1975) or treating them with respect (Tyler \& Blader, 2003) may indeed matter less when the distributive outcome is ultimately winner-take-all and the disputants belong to different social categories.

A notable real world example is final offer arbitration (Grigsby \& Bigoness, 1982; Kochan, 1980). In final offer arbitration, disputing parties each submit a proposal to the arbitrator after the final round of negotiation. The arbiter then chooses one side's proposal, which both parties are obliged to follow. In conventional arbitration, 
by contrast, an arbitrator works directly with both parties to craft a negotiated settlement. Because the cost of disagreement is so high in final offer arbitration, it generally leads to settlements with greater joint gains than does conventional arbitration (Bazerman \& Farber, 1985; Farber \& Bazerman, 1987; Neale \& Bazerman, 1983), because disputants are motivated to submit proposals that will ultimately be chosen by the arbitrator. However, our research suggests that final offer arbitration might be more difficult to utilize in inter-category disputes because of its winner-take-all qualities. Hence, people may prefer conventional arbitration in disputes that cross social category lines, rather than using the more deal-maximizing final offer form of arbitration.

\section{Future directions}

Future research could productively build upon our work both methodologically and theoretically. With respect to methodology, it would be desirable to explore reactions to winner-take-all outcomes in a non-scenario context. This would be especially helpful for gaining insights into the reactions of the disputants themselves, to complement findings on the pain of upward social comparison and unwillingness to tolerate disadvantageous inequality in inter-category allocations (Garcia, et al., 2005). For example, we could measure the actual hedonic gap experienced by winners and losers of a winner-take-all outcome, and perhaps even compare actual gaps with gaps perceived by third parties. Our scenario methodology, which by design was simple and artificial, is more appropriate for examining the reactions of third parties, who are usually more detached.

Although our analysis suggests that third party deciders are averse to resolving inter-category disputes with winner-take-all solutions because they are trying to preempt a hedonic gap, an important question remains-why does a hedonic gap matter to third party deciders in these situations? There are many possible answers. Creating a hedonic gap may be viewed as inherently unfair. Perhaps people don't like creating hedonic gaps because they seem to be promoting disharmony. Or perhaps third party deciders fear retaliation from the losing side. Admittedly, these and other reasons are likely to depend on the situation. A third party decider who is a political figure might be concerned about creating hedonic gaps for fear of retaliation, whereas a third party decider who is an ombudsperson might be concerned with hedonic gaps for the sake of fairness. Nevertheless, we did not investigate why hedonic gaps matter, and that remains an important research question.

Future research could also explore variables that are known to be important to the categorization process more broadly. These include crosscategorization (e.g. Crisp \& Hewstone, 1999), stereotypic preferences (e.g. Yzerbyt et al., 1997), and the meaningfulness of the social categories (e.g. McGarty, 1999). Researchers might also consider people's concern with appearing discriminatory (Pettigrew \& Meertens, 1995). For example, although Study 1 used a random coin toss as a winner-take-all solution, the outcome may have implied discrimination, despite the impartiality of the coin toss. Another important variable might be the perceived entitlement of the disputing groups to the contested resource. If people felt that the entitlement of one group was greater than that of the other group, then would they still be more reluctant to see the deserving group get everything? Consider a dispute between two countries. Imagine that the two countries were either both developed (or both developing), or that one was a developed country and the other a developing country. Would a third party be more averse to a winnertake-all outcome in the latter case? The answer is not obvious, especially if the third party thought the resource should be distributed on the basis of need (Weber, Kopelman, \& Messick, 2004).

Finally, a practical question remains: What is the minimum correlation between preferences and social categories needed to trigger the hedonic gap mechanism? For instance, if only $70 \%$ of the people in one social category want $\mathrm{A}$ and $70 \%$ of the people in another social category want $\mathrm{B}$, would one still be concerned about minimizing the hedonic gap? What if the percentages were $90 \%$ in one social category and $50 \%$ in the other? Future research should also 
explore whether the size of a social category matters. We focused on social categories that contain many members (e.g. nationality, state residence, etc.). Is the aversion effect weaker when the categories are smaller? Research on these and other issues will clarify the necessary minimum conditions for the aversion effect and perhaps even help policy makers, who often monitor public opinion across different demographic groups, to better predict when winner-take-all solutions will be more or less acceptable.

\section{Note}

1. By 'culture', we meant the customs and so on of a particular work group (see Levine \& Moreland, 1991). There was no evidence that participants had trouble understanding our meaning.

\section{Acknowledgements}

This research is based on a dissertation submitted by Stephen Garcia to Princeton University in partial fulfillment of the PhD in Psychology. Stephen Garcia was supported by graduate research fellowships from the National Science Foundation and the Program on Negotiation at Harvard Law School. The research was also supported by National Institute of Mental Health Grant MH44069. The authors wish to thank Max Bazerman, John Darley, Fred Feinberg, Susan Fiske, Sam Glucksberg, Debbie Prentice, Eldar Shafir, Frank Tong, Avishalom Tor, Kim Weaver and Oscar Ybarra for helpful comments. The authors also thank Elizabeth Brisson, Joshua Cregger, Bryan Harrison, Brian Hartmann, Mitch Meyle, Eric Provins, Alex Radetsky and Irina Yudovich for help with the data collection.

\section{References}

Abrams, D., \& Hogg, M.A. (1988). Comments on the motivational status of self-esteem in social identity and intergroup discrimination. European Journal of Social Psychology, 18, 317-34.

Abrams, D., \& Hogg, M.A. (1999). Social identity and social cognition. Oxford, UK: Blackwell.

Bazerman, M.H., \& Farber, H.S. (1985). Arbitrator decision making: When are final offers important? Industrial and Labor Relations Review, 39, 76-89.
Beggan, J.K., Platow, M.J., \& McClintock, C.G. (1991). Social interdependence. In R.A. Baron, W.G. Graziano, \& C. Stangor (Eds.), Social psychology (pp. 394-423). New York: Holt, Rinehart, \& Winston.

Blount, S. (1995). When social outcomes aren't fair: The effect of causal attributions on preferences. Organizational Behavior and Human Decision Processes, 63, 131-144.

Bolton, G.E., Brandts, J., \& Ockenfels, A. (2005). Fair procedures: Evidence from games involving lotteries. The Economic Journal, 115, 1054-1076.

Brewer, M.B. (1979). In-group bias in the minimal intergroup situation: A cognitive-motivational analysis. Psychological Bulletin, 86, 307-324.

Brickman, P., \& Bulman, R.J. (1977). Pleasure and pain in social comparison. In J.M. Suls \& R.L. Miller (Eds.), Social comparison processes: Theoretical and empirical perspectives. Washington, DC: Hemisphere.

Camerer, C. (1995). Individual decision making. In J.H. Kagel \& A.E. Roth (Eds.), Handbook of experimental economics (pp. 587-703). Princeton, NJ: Princeton University Press.

Crisp, R.J., \& Hewstone, M. (1999). Differential evaluation of crossed category groups: Patterns, processes, and reducing intergroup bias. Group Processes E Intergroup Relations, 2, 307-333.

Crisp, R.J., \& Hewstone, M. (2000). Crossed categorization and intergroup bias: The moderating roles of intergroup and affective context. Journal of Experimental Social Psychology, 36, 357-383.

Deaux, K. (1996). Social identification. In E.T. Higgins \& A.W. Kruglanski (Eds.), Social psychology: Handbook of basic principles (pp. 777-798). New York: Guilford.

Elster, J. (1989). Solomonic judgements. New York: Cambridge University Press.

Elster, J. (1992). Local justice. New York: Russell Sage Foundation.

Farber, H.S., \& Bazerman, M.H. (1987). Why is there disagreement in bargaining? The American Economic Review, 77, 347-352.

Garcia, S., Tor, A., Bazerman, M.H., \& Miller, D.T. (2005). Profit maximization versus disadvantageous inequality: The impact of self-categorization. Journal of Behavioral Decision Making, 18, 187-198.

Grigsby, D., \& Bigoness, W. (1982). The effects of third party intervention on pre-intervention bargaining behavior. Journal of Applied Psychology, 67, 549-554. 
Haddock, G., \& Zanna, M.P. (1998). On the use of open-ended measures to assess attitudinal components. British Journal of Social Psychology, 37, 129-149.

Haslam, S.A., McGarty, C., \& Brown, P.M. (1996). The search for differentiated meaning is a precursor to illusory correlation. Personality and Social Psychology Bulletin, 22, 611-619.

Hogg, M.A., \& Abrams, D. (1990). Social motivation, self-esteem and social identity. In D. Abrams \& M.A. Hogg (Eds.), Social identifications: Constructive and critical advances (pp. 28-47). London: Harvester Wheatsheaf.

Kenny, D.A., Kashy, D.A., \& Bolger, N. (1998). Data analysis in social psychology. In D. Gilbert, $\mathrm{S}$. Fiske, \& G. Lindzey (Eds.), The handbook of social psychology (Vol. 1, 4th ed., pp. 233-265). Boston: McGraw-Hill.

Kochan, T.A. (1980). Collective bargaining and organizational behavior research. In B. Staw \& L. Cummings (Eds.), Research in organizational behavior (Vol. 2, pp. 129-176). Greenwich, CT: JAI Press.

Levine, J.M., \& Moreland, R.L. (1991). Culture and socialization in work groups. In L.B. Resnick, J.M. Levine, \& S.D. Teasdale (Eds.), Perspectives on socially shared cognition (pp. 257-279). Washington, DC: American Psychological Association.

Lind, E.A., \& Tyler, T.R. (1988). The social psychology of procedural justice. New York: Plenum.

McGarty, C. (1999). Categorization in social psychology. London: Sage.

Neale, M.A., \& Bazerman, M.H. (1983). The role of perspective-taking ability in negotiating under different forms of arbitration. Industrial and Labor Review, 36, 378-388.

Nisbett, R.E., \& Wilson, T.D. (1977). Telling more than we can know: Verbal reports on mental processes. Psychological Review, 84, 231-259.

Pettigrew, T. F., \& Meertens, R. W. (1995). Subtle and blatant prejudice in western Europe. European Journal of Social Psychology, 25, 57-75.

Prentice, D. A., \& Miller, D. T. (2006). Inferences about differences that cross social category boundaries. Psychological Science, 17, 129-135.

Raiffa, H. (1982). The art and science of negotiation. Cambridge, MA: Harvard University Press.

Schopler, J., Insko, C., Drigotas, S.M., Wieselquist, J., Pemberton, M.B., \& Cox, C. (1995). The role of identifiability in the reduction of interindividual-intergroup discontinuity. Journal of Experimental Social Psychology, 31, 553-574.
Tajfel, H. (1969). Cognitive aspects of prejudice. Journal of Social Issues, 25, 79-97.

Tajfel, H. (1981). Human groups and social categories: Studies in social psychology. Cambridge, UK: Cambridge University Press.

Thibaut, J., \& Walker, L. (1975). Procedural justice. Hillsdale, NJ: Erlbaum.

Turner, J.C., Hogg, M.A., Oakes, P.J., Reicher, S.D., \& Wetherell, M.S. (1987). Rediscovering the social group: A self-categorization theory. Oxford: Basil Blackwell.

Tyler, T.R., \& Blader, S.L. (2003). The group engagement model: Procedural justice, social identity, and cooperative behavior. Personality and Social Psychology Review, 7, 349-361.

Weber, M., Kopelman, S., \& Messick, D. (2004). A conceptual review of decision making in social dilemmas: Applying the logic of appropriateness. Personality and Social Psychology Review, 8, 281-307.

Wenzel, M. (2001). A social categorization approach to distributive justice: Social identity as the link between relevance of inputs and need for justice. British Journal of Social Psychology, 40, 315-335.

Wenzel, M. (2002). What is social about justice? Inclusive identity and group values as the basis of the justice motive. Journal of Experimental Social Psychology, 38, 205-218.

Yzerbyt, V.Y., Rocher, S., \& Schadron, G. (1997). Stereotypes as explanations: A subjective essentialistic view of group perception. In R. Spears, P.J. Oakes, N. Ellemers, \& S.A. Haslam (Eds.), The social psychology of stereotyping and group life (pp. 20-50). Oxford, UK: Blackwell.

Paper received 6 November 2005; revised version accepted 20 March 2007.

\section{Biographical Notes}

STEPHEN GARCIA is an assistant professor of public policy at the Gerald R. Ford School of Public Policy at the University of Michigan and faculty associate at the Research Center for Group Dynamics. Stephen teaches courses on negotiation at the Ford School and Ross School of Business.

DALE Miller is Morgridge Professor of Organizational Behavior at the Graduate School of Business and professor of psychology at Stanford University. Dale teaches a course entitled 'Beyond Self Interest Motivation'. 